\title{
INTERPRETASI HASIL ANALISA PRODUK SOLAR 48 DENGAN PARAMETER APPEARANCE, DISTILLATION, VISCOSITY KINEMATIC DAN POUR POINT DI PT PERTAMINA (PERSERO) REFINERY UNIT IV CILACAP
}

\author{
INTERPRETATION OF SOLAR 48 PRODUCT ANALYSIS RESULTS WITH PARAMETERS \\ APPEARANCEZDISTLATIONX VISCOSITY KINEMATIC, AND POUR POINTS IN PT \\ PERTAMINA (PERSERO) UNIT IV CILACAP
}

\author{
Ineke Febrina A. ${ }^{1)}$, Fahrul Yamin ${ }^{2)}$ \\ 1Program Studi Teknik Analisis Laboratorium Migas Politeknik Akamigas Palembang, 30257, Indonesia \\ 2Program Studi Teknik Analisis Laboratorium Migas Politeknik Akamigas Palembang, 30257, Indonesia
}

\begin{abstract}
Diesel oil is a type of clear brownish yellow distillate with a cetane index of not less than 48 (> 48). This diesel oil can also be called Automotive Diesel Oil (ADO) or High Speed Diesel Oil (HSD). Diesel oil is one of the fuels used by the people of Indonesia, both the general public, fishermen, industry, agriculture and so on. Generally, diesel oil is used to meet the fuel needs of vehicles that use diesel engines with a spin greater than $1000 \mathrm{rpm}$. The specifications of diesel oil consist of several analyzes with certain limitations which have been determined by the Director General of Oil and Gas in his letter No. 4769/10 / DJM.T / 2012. Analysis of this diesel oil was carried out with two samples given by the supervisor which included appearance, distillation, viscosity kinematic and pour point. Based on the results of the analysis conducted, the results obtained are that in sample A and sample B there is a slight difference, but the difference still meets the specifications set by the Director General of Oil and Gas in the analysis in testing sample A and sample B.

Keywords: 48 diesel oil, Specifications, Appearance, Distillation, Viscosity Kinematic and Pour Point
\end{abstract}

Abstrak: Minyak solar merupakan bahan bakar jenis distilat berwarna kuning kecoklatan yang jernih dengan cetane indextidak kurang dari 48 (>48). Minyak solar ini bisa disebut juga Automotive Diesel Oil (ADO) atau High Speed Diesel Oil (HSD). Minyak solar merupakan salah satu bahan bakar yang digunakan masyarakat Indonesia,baik kalangan umum, nelayan, industri, pertanian dan sebagainya. Umumnya minyak solar digunakan untuk memenuhi kebutuhan bahan bakar kendaraan yang menggunakan mesin diesel dengan putaran yang lebih besar dari 1000 rpm. Spesifikasi minyak solar terdiri atas beberapa analisa dengan batasan tertentu yangtelah ditetapkan oleh Dirjen Migas dengan suratnya No. 4769/10/DJM.T/2012. Analisa terhadap minyak solar ini dilakukan dengan dua sampel yang diberikan oleh pembimbing yang meliputi appearance, distillation,viscosity kinematic dan pour point. Berdasarkan hasil analisis yang dilakukan, hasil yang diperoleh yaitu pada sampel A dan sampel B adanya perbedaan sedikit, namun perbedaan tersebut masih memenuhi spesifikasi yang telah ditetapkan Dirjen Migas pada analisa dalam pengujian sampel A dan sampel $B$.

Kata Kunci : Minyak solar 48, Spesifikasi, Appearance, Distillation, Viscosity Kinematic dan Pour Point

\section{PENDAHULUAN}

\subsection{Latar Belakang}

Minyak solar merupakan salah satu bahan bakar yang digunakan masyarakat Indonesia, baik kalangan umum, nelayan, industri, pertanian dan sebagainya. Umumnya minyak solar digunakan untuk pemenuhan kebutuhan bahan bakar kendaraan yang menggunakan mesin diesel dengan putaran yang lebih besar dari $1000 \mathrm{rpm}$. Sistem penyalaan motor diesel dilakukan dengan sistem penyalaan kompresi, yaitu sistem
Internal Combustion Engine. Minyak solar ini biasa disebut juga Automotive Diesel Oil (ADO) atau High Speed Diesel (HSD). Bahan bakar diesel secara umum adalah bahan bakar yang dapat digunakan di mesin diesel. Bahan bakar yang paling banyak digunakan adalah minyak diesel dan juga minyak solar. Namun, terdapat juga alternatif lain yaitu biodiesel, biomass to liquid (BTL) diesel, ataupun gas to liquid (GTL) diesel yang sedang dalam perkembangan. Hal ini dimaksudkan agar emisi yang dihasilkan dari proses pembakaran 
diesel fuel hanya mengandung sedikit kandungan sulfur.

Mengingat semakin besarnya produksi bahan bakar solar, maka perlu dilakukan kontrol terhadap mutu bahan bakar solar yang diproduksi. Untuk mengetahui mutu dari bahan bakar solar dilakukan pengujian dari beberapa parameter uji yang termasuk kritikal, meliputi : sifat kebersihan, sifat kemudahan mengalir dan sifat penguapan. Adanya batasan-batasan spesifikasi yang telah ditetapkan, harus dipenuhi oleh produsen untuk menjaminmutu produk yang dihasilkan agar kepuasan konsumen dapat terpenuhi yang berkaitan aplikasi terhadap kendaraan dan konsumen tidak dirugikan. Proses pengujian dilakukan dengan menggunakan metode standar baku yaitu ASTM (American Society for Testing and Materials).

Minyak diesel merupakan hasil penyulingan minyak yang berwarna hitam dan berbentuk cair pada temperatur rendah, dengan cetane index 40-45. Biasanya memiliki kandungan sulfur yang rendah dan dapat digunakan untuk Medium Speed Diesel Engine di sektor industri. Selain itu, minyak diesel juga memiliki boiling point yang tidak terlalu rendah dan tidak terlalu tinggi. Oleh karena itu, minyak diesel disebut juga Industrial Diesel Oil (IDO) atau Marine Diesel Fuel (MDF). Minyak solar dari PT. Pertamina (Persero) RU IV Cilacap merupakan minyak campuran dari berbagai hasil stream, seperti Heavy Diesel Oil (HDO), Light Diesel Oil (LDO), Heavy Gas Oil (HGO) dan Light Gas Oil (LGO). Berdasarkan uraian tersebut penulis tertarik untuk mengetahui lebih dalam tentang bahan bakar solar dengan judul, Interprestasi Hasil Analisa Appearance, Distillation, Viscosity Kinematic dan Pour Point. Terhadap Jaminan mutu Produk Solar di PT Pertamina (Persero) RU IV Cilacap.

\subsection{Batasan Masalah}

Pada penelitian ini penulis membatasi permasalahan pada Interprestasi Hasil Analisa Produk Solar dengan parameter Appearance, Distillation, Viscosity Kinematic dan Pour Point.

\subsection{Tujuan Penelitian}

Tujuan dari penelitian ini adalah :

1. Menghitung perbandingan hasil analisis antara sampel A dan sampel B dari produk solar berdasarkan parameter, Appearance, Viscositas Kinematic, Distillation dan Pour Point.

2. Interpretasi hasil pengujian minyak solar sesuai spesifikasi menurut ketetapan Dirjen Migas.

\subsection{Manfaat Penelitian}

Manfaat dari penelitian ini adalah

1. Dapat mengetahui hasil analisa Appearance, Viscosity Kinematic, Distillation dan Pour Point.

2. Dapat mengetahui sifat kebersihan secara visual.

3. Dapat mengetahui mudah atau tidaknya sampel tersebut mengalir atau dipompakan.

4. Dapat mengetahui sifat penguapan pada produk solar.

\section{TEORI DASAR}

\subsection{Pengertian Minyak Solar}

Minyak solar merupakan bahan bakar jenis distilat berwarna kuning kecoklatan yang jernih dengan cetane index tidak kurang dari 48 (>48). Penggunaan minyak solar ini pada umumnya adalah untuk bahan bakar pada semua jenis mesin diesel dengan putaran tinggi (>1000 rpm). Minyak solar ini biasa disebut juga Automotive Diesel Oil (ADO) atau High Speed Diesel Oil (HSD).

\subsection{Proses Pembuatan Minyak Solar di RU IV Cilacap}

Minyak solar dari RU IV dibuat dari campuran beberapa komponen dari campuran beberapa komponen dari stream baik dari Fuel Oil Complex (FOC) I maupun Fuel Oil Complex (FOC) II. Pencampuran dilakukan sebelum masuk ke tangki (in line blending) yang secara detailnya dapat digambarkan dalam diagram pada gambar 2.1. 


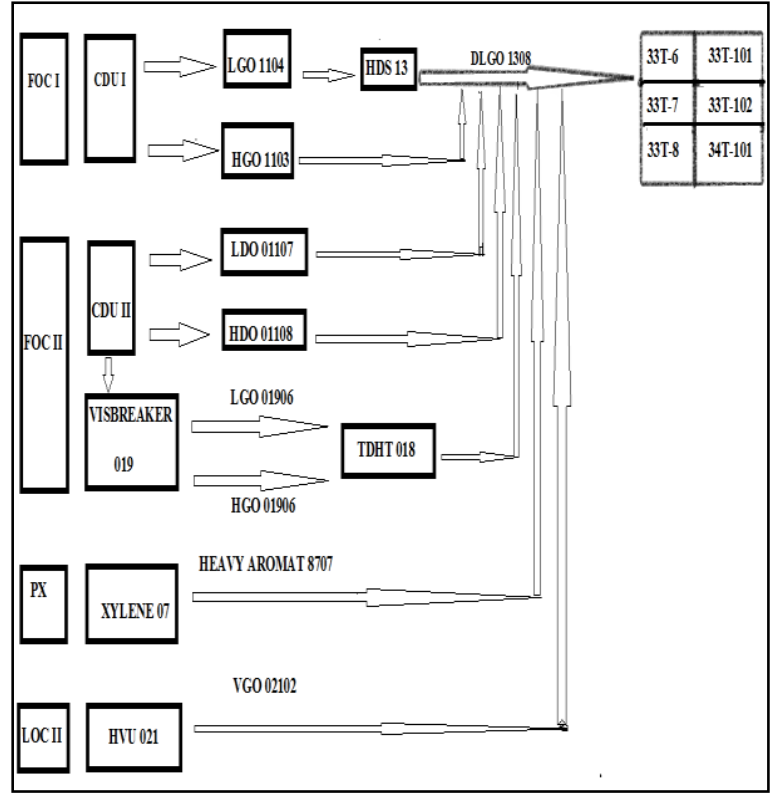

Gambar 2.1 Proses Pembuatan Minyak Solar di RU IV Cilacap

\section{METODOLOGI PENELITIAN}

\subsection{Waktu dan Tempat Penelitian}

Penelitian ini dilaksanakan pada tanggal 06 s.d. 28 April 2017 berlokasi di Laboratorium Fuel and Non Fuel PT PERTAMINA (Persero) RU IV Cilacap.

\subsection{Teknik Pengumpulan Data}

Dalam mendapatkan data-data yang berhubungan dengan obyek yang diteliti, penulis menggunakan teknik pengumpulan data sebagai berikut:

\section{Studi Pustaka}

Metode yang digunakan dengan cara mengumpulkan sumber-sumber berupa literatur yang terdapat pada buku, jurnal yang mendukung penelitian ini.

\section{Metode Observasi (Studi Lapangan)}

Metode yang digunakan dengan cara pengamatan langsung atau melaksanakan pengujian langsung parameter appearance, distillation, viscosity kinematic dan pour point di PT Pertamina (Persero) RU IV Cilacap.

\section{Wawancara}

Metode yang digunakan dengan menerapkan sistem pemberian materi dan penjelasan dari pembimbing lapangan, asisten maupun karyawan yang menguasai bidangnya masing-masing. Selain itu, metode ini merupakan metode diskusi untuk mendiskusikan materi yang belum jelas dengan cara melakukan proses tanya jawab sesuai dengan teori dan pengalaman lapangan.

\subsection{Skema Penelitian}

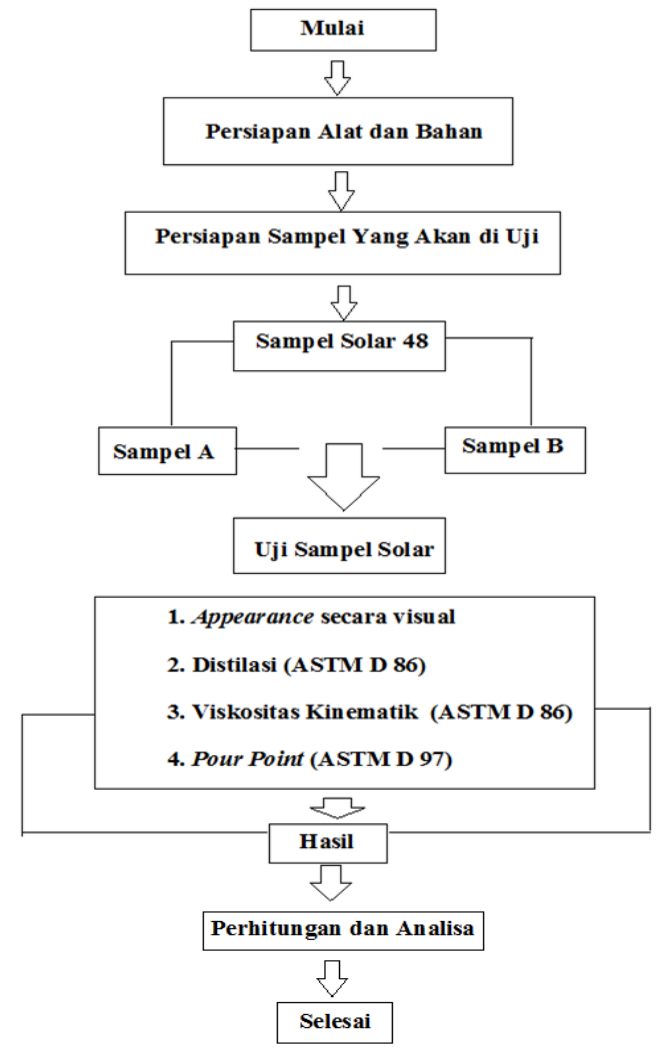

\section{Gambar 3.1 Skema Penelitian}

\subsection{Metode Pengujian}

\subsubsection{Analisa Appearance Secara Visual} a. Tujuan

Metode ini bertujuan untuk menentukan appearance secara visual dari produk, agar tercapai keseragaman dalam penentuan/pengujian dan keseragaman dalam pelaporan hasil pengujian.

b. Alat

Alat yang dipakai pada penelitian ini antara lain:

1. Botol putih terang dan tembus pandang kapasitas 1 Liter, dan

2. Lampu penerang.

c. Bahan

Bahan yang digunakan pada penelitian ini, yaitu: sampel solar.

d. Prosedur

Prosedur kerja yang dilakuan pada penelitian ini sebagai berikut: 
1. Sampel dituang kedalam botol putih bersih dan tembus pandang.

2. Sampel diamati dengan bantuan pencahayaan serta dibandingkan dengan warna produk yang bersih dan tidak tercemar oleh kotoran (tidak terdapat partikel dan air yang teremulsi).

\subsubsection{Distilasi (ASTM D 86)}

\section{a. Tujuan}

Metode uji ini bertujuan untuk mengetahui secara kuantitatif karakteristik rentang titik didih, residu dan recovery yang hilang dari produk petroleum dengan alat distilasi manual pada tekanan atmosferik.

b. Alat antara lain:

Alat yang dipakai pada penelitian ini

1. Labu distilasi $125 \mathrm{ml}$,

2. Kondensor dan Bak Pendingin,

3. Pemanas,

4. Gelas ukur kapasitas $100 \mathrm{ml}$ dan $5 \mathrm{~m}$,

5. Penyangga labu distilasi diameter $50 \mathrm{~mm}$

6. Shield,

7. Pembersih kondensor,

8. TermometerASTM $8 \mathrm{C}$ atau $8 \mathrm{~F}$, dan

9. Jar bath.

c. Bahan

Bahan yang digunakan pada penelitian ini, yaitu: sampel solar.

d. Prosedur

Prosedur kerja yang dilakuan pada penelitian ini sebagai berikut:

1. Sebanyak $100 \mathrm{ml}$ sampel ditakar dengan gelas ukur kapasitas $100 \mathrm{ml}$.

2. Sampel dimasukkan kedalam labu distilasi dan termometer dipasang.

3. Labu distilasi yang telah berisi sampel dipasang diatas penyangga labu pada peralatan distilasi.

4. Gelas ukur dipasang persis dibawah ujung kondenser.

5. Alat pemanas dihidupkan dan pemanasan diatur sesuai dengan kondisi pemeriksaan.

6. Suhu dimana tetesan pertama dari kondesat timbul (menetes) dicatat sebagai Initial Boiling Pointl IBP dengan ketelitian $1{ }^{\circ} \mathrm{C}$.
7. Suhu pada tiap persen volume recovery $10,20,30,40,50,60,70,80,90$, dicatat.

8. Alat pemanas dimatikan dan labu distilasi dibiarkan menjadi dingin.

9. Sisa sampel yang ada dalam labu distilasi dituang kedalam gelas ukur kapasitas 5 $\mathrm{ml}$, \% volume yang didapat dicatat sebagai residu.

10. \% volume loss dihitung dengan formula: $\%$ loss $=100-($ total recovery + residu $)$

11. Data-data hasil pengujian dicatat.

\subsubsection{Viskositas Kinematik (ASTM D 445)}

a. Tujuan

Metode uji ini untuk pengujian viskositas kinematik dari produk petroleum cair, baik transparan dan atau buram, dengan mengukur waktu untuk volume cairan yang mengalir dengan gaya gravitasi melalui viskometer kapiler yang terkalibrasi.

b. Alat

Alat yang dipakai pada penelitian ini antara lain:

1. Viskometer,

2. Kedudukkan viskometer (Viscometer Holder),

3. Bath,

4. Temperatur kontrol, dan

5. Termometer.

c. Bahan

Bahan yang digunakan pada penelitian ini, yaitu: sampel solar.

d. Prosedur

Prosedur kerja yang dilakuan pada penelitian ini sebagai berikut:

1. Viskometer terkalibrasi disiapkan, dengan faktor dan jenis yang sesuai dengan sampel yang akan diuji.

2. Sampel dimasukkan secukupnya (agar pada saat temperatur tercapai isinya / volumenya tepat berada pada tanda batas) ke dalam viskometer.

3. Viskometer yang telah diisi tersebut didiamkan didalam bath minimal selama 30 menit agar temperatur sampel sama dengan temperatur bath.

4. Dengan menggunakan selang vacuum, sampel ditarik ke atas sampai kurang lebih 
$7 \mathrm{~mm}$ di atas tanda batas awal pada viskometer kemudian selang vacuum dilepaskan dan sampel dibiarkan mengalir bebas.

5. Waktu alir sampel dicatat dimulai saat sampel tepat melalui tanda batas awal pada viskometer dan pencatatan waktu alir sampel diakhiri saat sampel tepat melalui tanda batas akhir yang tertera pada viskometer.

\subsubsection{Pour Point (ASTM D 97)}

a. Tujuan

Metode uji ini untuk pengujian pour point (titik tuang) beberapa produk crude oil. b. Alat

Alat yang dipakai pada penelitian ini antara lain:

1. Test jar,

2. Termometer,

3. Cork (gabus), dan

4. Pour point bath.

c. Bahan

Bahan yang digunakan pada penelitian ini, yaitu:

1. Sampel solar,

2. Etanol, Metanol, Isopropil Alkohol (IPA),

3. Aseton,

4. Petroleum Naphtha,dan

5. Solid Carbon Dioxide.

d. Prosedur

Prosedur kerja yang dilakuan pada penelitian ini sebagai berikut:

1. Sampel dituang kedalam test jar sampai tanda batas.

2. Test jar ditutup dengan gabus yang telah dilengkapi dengan termometer dan jacket, posisi termometer diatur sedemikian rupa sehingga bulb Mercury berada $3 \mathrm{~mm}$ dibawah permukaan sampel.

3. Pengamatan pour point dari sampel di mulai sebagai berikut :

a. Untuk sampel-sampel yang pour point di atas $-33{ }^{\circ} \mathrm{C}$, test jar dipindahkan ke bath yang suhu/temperaturnya $24^{\circ} \mathrm{C} \pm 1,5^{\circ} \mathrm{C}$. Test jar yang berisi sampel diangkat sedemikian rupa sehingga posisi sampel dan termometer tidak berubah/goyang. b. Posisi test jar pada saat akan dibaca sampel dimiringkan dan diamati perubahan sampelnya. Bila sampel masih mengalir test jar segera dikembalikan kembali kedalam bath pendingin. Waktu pelaksanaan pengamatan sampai dengan pengembalian ke bath pendingin tidak lebih dari 3 detik.

c. Pengamatan tersebut di atas dilakukan terus setiap penurunan temperatur sampel kelipatan $3^{\circ} \mathrm{C}$.

4. Bila sampai dengan suhu/temperatur $24^{\circ} \mathrm{C}$ sampel masih mengalir saat diamati, test jar tersebut dipindahkan ke bath yang lebih dingin, demikian secara terus menerus dengan aturan sebagai berikut :

a. Start s.d. $+9{ }^{\circ} \mathrm{C}$ pindahkan ke bath dengan temperatur $0^{\circ} \mathrm{C}$

b. +9 s.d. $-6^{\circ} \mathrm{C}$ pindahkan ke bath dengan temperatur $-18^{\circ} \mathrm{C}$

c. -6 s.d. $-24{ }^{\circ} \mathrm{C}$ pindahkan ke bath dengan temperatur $-33^{\circ} \mathrm{C}$

d. -24 s.d. $-42{ }^{\circ} \mathrm{C}$ pindahkan ke bath dengan temperatur $-51{ }^{\circ} \mathrm{C}$

5. Bila pada pengamatan dalam kondisi test jar dimiringkan sampel tidak bergerak (mengalir) test jar tersebut segera diluruskan sampai posisi horizontal selama 5 detik. Bila masih ada gerakan dari sampel, test jar tersebut diletakkan kembali secepatnya kedalam bath untuk didinginkan kembali.

6. Pengamatan terhadap gerakan (aliran) sampel diulangi untuk setiap penurunan temperature $3{ }^{\circ} \mathrm{C}$ sampai tercapai kondisi dimana sampel tidak bergerak / mengalir selama 5 detik bila diposisikan pada posisi horizontal.

7. Pembacaan suhu/temperatur pengamatan pada kondisi tersebut diatas dicatat sebagai pour point.

\section{HASIL DAN PEMBAHASAN \\ 4.1 Hasil Analisa}

Setelah dilakukan pemeriksaan selama 22 hari, dimulai sejak tanggal 06 April s.d. 28 April 2017 terhadap produk minyak solar sesuai parameter, appearance, pour point, 
viscosity kinematic dan distillation, maka didapatkan data sebagai berikut : parameter appearance, pour point, viscosity kinematic dan distillation, maka didapatkan data sebagai berikut :

Tabel 4.1 Parameter Appearance, Pour Point, Viscosity Kinematic dan Distillation

\begin{tabular}{|c|c|c|c|c|c|c|}
\hline \multirow{2}{*}{ 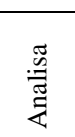 } & \multirow{2}{*}{ 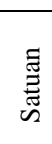 } & \multirow{2}{*}{ 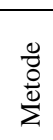 } & \multicolumn{2}{|c|}{ Hasil Analisa } & \multicolumn{2}{|c|}{ Batasan } \\
\hline & & & A & B & Min & Maks \\
\hline 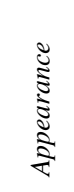 & ' & 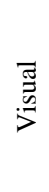 & 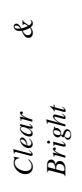 & 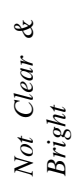 & Clear & Bright \\
\hline 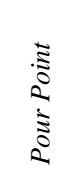 & U & 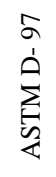 & $a$ & $\simeq$ & ' & $\stackrel{\infty}{-1}$ \\
\hline 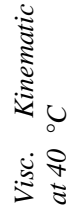 & 苞 & 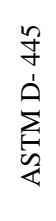 & $\begin{array}{l}\infty \\
\stackrel{\infty}{\infty} \\
\dot{m}\end{array}$ & $\begin{array}{l}\text { त్ర్రి } \\
\text { in }\end{array}$ & i & ir \\
\hline 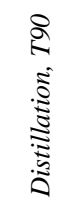 & 0 & 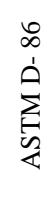 & ळ & 总 & ' & $\stackrel{2}{n}$ \\
\hline
\end{tabular}

\subsection{Pembahasan}

\subsubsection{Analisa Appearance Secara Visual}

Appearance secara visual ini adalah penentuan warna produk minyak bumi digunakan terutama untuk keperluan kontrol pabrik dan suatu ciri mutu yang penting karena warna paling mudah diamati. Dalam beberapa kasus warna sebagai indikasi dari tingkat kemurnian bahan. Bila kisaran warna produk diketahui, variasi di luar kisaran yang ditentukan dapat merupakan indikasi kemungkinan terkontaminasi dengan produk lain, tetapi warna tidak selalu menunjukkan mutu suatu produk.

Dari pengujian appearance secara visiual ini dapat di interpretasi bahwa kita dapat mengetahui tampilan bentuk secara fisik sampel tersebut, apabila sampel tersebut dari tampilan, warna sudah berbedah dari warna produk yang telah ditetapkan berarti sampel tersebut terindikasi / terkontaminasi minyak ringan maupun minyak berat.

\subsubsection{Analisa Pour Point ASTM D-97}

Pour point adalah suhu terendah saat bahan bakar minyak masih dapat mengalir dengan sendirinya pada kondisi analisis. Pour Point diperlukan sehubungan dengan adanya persyaratan praktis dari penyimpanan (storage) dan penggunaan dari bahan bakar. Hal ini dikarenakan bahan bakar sering sulit untuk dipompa, apabila suhunya telah di bawah pour point.

Kemudahan mengalir minyak solar dipengaruhi oleh komposisi hidrokarbon dalam bahan bakar itu. Sedangkan kegagalan untuk mengalir pada pour point umumnya berhubungan dengan kandungan lilin dari minyak, tetapi dapat juga karena pengaruh viskositas minyak yang sangat kental. Bahan bakar yang banyak mengandung parafin (lilin) akan lebih mudah membeku dibandingkan dengan bahan bakar yang kandungan parafinnya rendah.

Dari pengujian pour point ini dapat diinterpretasikan bahwa pour point adalah suhu terendah dimana bahan bakar masih dapat mengalir. Sifat ini memberikan indikasi tentang sifat pemompaan pada suhu terendah. Nilai pour point untuk minyak solar sesuai dengan spesifikasi maksimum $18{ }^{\circ} \mathrm{C}$. Bila hasil pengujian lebih besar dari $18{ }^{\circ} \mathrm{C}$, berarti minyak solar mempunyai nilai pour point tinggi. Dalam minyak solar ini mengandung komponen parafin (lilin), sehingga pada suhu pengkabutan dihasilkan kristal-kristal lilin. Ini akan memberikan indikasi tentang suhu pada saat dimana akan terjadi penyumbatan saringan oleh kristal lilin. Minyak solar yang baik mempunyai pour point $8-10{ }^{\circ} \mathrm{C}$ di bawah titik kabut. Dari hasil analisa yang didapatkan pada sampel A dan sampel B mempunyai perbedaan sedikit, yaitu sampel A $9{ }^{\circ} \mathrm{C}$ dan sampel B $18{ }^{\circ} \mathrm{C}$ tetapi semuanya masuk spesifikasi yang telah ditetapkan.

\subsubsection{Analisa Viscosity Kinematic ASTM D-445}


Viscosity Kinematic adalah tahanan cairan untuk mengalir karena gaya gravitasi. Metode ini mencakup penentuan viscosity kinematic cairan petroleum product yang transparan maupun yang gelap dengan batasan 0,2 s.d $300.000 \mathrm{cSt}$, dengan mengukur waktu volume tertentu dari cairan yang mengalir karena gravitasi pada suatu kapiler viskometer yang terbuat dari kaca yang terkalibrasi.

Kebanyakan produk-produk minyak bumi dan beberapa material bukan minyak bumi digunakan sebagai pelumas dan operasi yang benar dari peralatan bergantung pada kesesuaian viskositas cairan yang diperlukan. Di samping itu, viskositas dari kebanyakan minyak bakar penting untuk kepentingan estimasi kondisi optimal penyimpanan, penanganan dan operasional. Dengan demikian, pengukuran viskositas yang tepat penting untuk kebanyakan spesifikasi produk.

Dari pengujian ini dapat diinterpretasi bahwa viskositas ini penting untuk diketahui karena berhubungan sifat pemompaan dan sistem injeksi bahan bakar ke ruang bakar mesin. Nilai viskositas pada spesifikasi minyak solar adalah min. 2,0 dan maks. 5,0 cSt. Bila hasil pengujian diperoleh nilai sesuai dengan spesifikasi, tidak mendatangkan masalah pada pemompaan dan pembentukan kabut di ruang bakar mesin. Bila hasil pengujian diperoleh nilai kurang dari 2,0 cSt, minyak solar mempunyai viskositas encer berarti banyak mengandung fraksi ringan, sehingga boros dalam pemakaiannya, walaupun kerja pompa ringan.

Sebaliknya bila hasil pengujian diperoleh nilai lebih besar dari 5,0 cSt, minyak solar mempunyai viskositas tinggi (pekat) berarti mengandung fraksi berat, minyak solar sulit untuk dikabutkan dan kerja pompa berat. Dari hasil analisa yang diperoleh pada pengujian sampel A dan sampel B adanya perbedaan sebagian kecil, yaitu sampel A 3,785 dan sampel B 3,625 tetapi keduanya masih masuk dalam spesifikasi yaitu minimum 2,0 dan maksimum 5,0.

Sifat mutu penguapan pada minyak solar meliputi distillation, (ASTM D-86). Distillation pada dasarnya adalah menguapkan cairan uji dengan cara dipanaskan, kemudian uapnya didinginkan untuk menghasilkan distilat. Sifat volatilitas (distillation) hidrokarbon mempunyai pengaruh yang penting untuk keselamatan dan untuk kerja, khususnya untuk bahan bakar distillation dan solvent. Kisaran titik didih memberikan informasi terhadap komposisi, sifat-sifat dan perilaku bahan bakar minyak selama penyimpanan dan penggunaan. Selain itu, analisis distillation ini juga sebagai indikasi adanya kontaminasi oleh adanya fraksi ringan atau berat. Minyak solar 48 yang memiliki sifat penguapan yang terlalu tinggi, berarti minyak solar tersebut ada kemungkinan terkontaminasi oleh produk kerosene / minyak ringan

Dari pengujian ini dapat di interpretasi bahwa dalam spesifikasi minyak solar, pada saat pembacaan temperatur dilakukan pada saat initial boiling point (IBP) dan setiap penambahan $10 \%$ volume kondesat, sampai dengan $90 \%$ volume recovery, tidak ada batasan minimum melainkan adanya batasan maksimum. Pada dasarnya bila sifat penguapan bahan bakar terlalu rendah, bahan bakar sukar untuk diatomisasikan sehingga akan menurunkan tenaga yang dihasilkan. Sebaliknya bila sifat penguapan bahan bakar terlalu tinggi, bahan bakar mudah untuk diatomisasikan berarti di dalam ruang bakar mesin banyak uap yang dihasilkan sehingga mengakibatkan penurunan tenaga, karena vapor lock dan disamping itu juga dapat menyebabkan terjadinya detonasi dan keborosan, serta pengujian distilasi ini mengindikasikan terjadinya kontaminasi bahan bakar tersebut oleh fraksi yang lebih ringan atau fraksi yang lebih berat. Dari pengujian yang telah dilakukan didapatkan hasil pengujian sampel A 358 dan sampel B 356 dari hasil ini menunjukan adanya perbedaan sebagian kecil, tetapi perbedaan tersebut masih masuk dalam spesifikasi yang memiliki batasan maksimum $370 \%$ recovery.

\section{KESIMPULAN DAN SARAN 5.1 Kesimpulan}


Dari pembahasan tersebut, maka kesimpulan dari penelitian ini, yaitu :

1. Berdasarkan hasil pengujian sampel A dan sampel B adanya perbedaan sifat pengujian pada parameter appearance, distillation sampel A 358 dan sampel B. 356 yang batasan maksimumnya $370 \%$ recovery, viscosity kinematic sampel $\mathrm{A}$. 3,785 dan sampel B 3,626 yang mempunyai batasan minimum 2.0 dan maksimum 5,0 dan pour point sampel A. $9{ }^{\circ} \mathrm{C}$ dan sampel B $12{ }^{\circ} \mathrm{C}$ yang batasan maksimumnya $18{ }^{\circ} \mathrm{C}$, tetapi tidak terlalu besar perubahan yang terjadi antara sampel A dan sampel B.

2. Dari hasil pengujian sampel A dan sampel B sesuai spesifikasi yang telah ditetapkan Dirjen Migas No. 4769/10/DJM. T/2012 Revisi 10, tanggal 25 Juni 2012.

\subsection{Saran}

Saran yang dapat diberikan dari penelitian ini, yaitu disarankan untuk dilakukan penelitian lanjutan pada produk solar 48 terhadap appearance, distillation, viscosity kinematic dan pour point.

\section{DAFTAR PUSTAKA}

American Society for Testing Materials.2008. Annual Book of ASTM Standard Petroleum Pruduct, Lubricants \& Fossil Fuels, Volume 05, Philadelpia.

Budiana, Basit. 2008. Kertas Kerja Wajib (KKW) Spesifikasi dan Interpretasi Minyak Solar 48. Cilacap: Laboratorium PT Pertamina (Persero) RU IV.

Dirjen Migas. 2012. Spesifikasi Finishing Product Minyak solar 48. Dalam Surat Dirjen Migas No. 4769/10DJM. T 2012 Revisi 10, tanggal 25 Juni 2012.

Mudjirahrdjo. 2003. Signifikansi Pengujian BBM Umum. Cepu: Pusat Pendidikan dan Pelatihan Minyak dan Gas Bumi (PUSDIKLAT MIGAS).
Prayitno, Edy. 2006. Kimia Minyak Bumi dan Hidrokarbon. Plaju: PT Pertamina.

Vagabon, John. 2008. Fractional Distillation. http:/johnvagabonscience.

Wordpress.com/2008/09/08/fractional-

distillation.html. Diakses pada April 2017. 
P-ISSN: 2089-5925 E-ISSN: 2621-9328

Antrant

Jurnal Teknik Patra Akademika

PATA

LII I 